\title{
Growth of piezoelectric thin films by sputtering
}

\author{
D. REMIENS, B. JABER and P.Y. JOUAN
}

Université de Valenciennes, CRITT Maubeuge, Laboratoire des Matériaux Industriels, BP. 311, 59304 Valenciennes cedex, France

\begin{abstract}
Lead titanate thin films have been deposited on different substrates by radio frequency magnetron sputtering from pressed powders targets. The films have been deposited without substrate heating. The amorphous films were then annealed in order to obtain the perovskite structure. Two types of post-annealing were study : conventional annealing and rapid thermal annealing (R.T.A.). The main advantage of the RTA process is to avoid (or to limit) the problem of interdiffusion or of interfacial disturbance between the substrate (in particular Silicium substrate) and the lead titanate thin film. The composition, structure and microstructure of PT films were evaluated as a function of the annealing parameters for conventional and rapid annealing.
\end{abstract}

\section{1- INTRODUCTION}

Lead titanate (PT) is a well known ferroelectric material showing large piezoelectric, pyroelectric and electro-optic effects. Recently considerable attention has been focused on piezoelectric thin films because of their many possible applications to electronic, optoelectronic and integrated devices. Several techniques such as evaporation ${ }^{1}$, R.F. sputtering ${ }^{2}$, ion beam sputtering ${ }^{3}$, laser ablation ${ }^{4}$, sol-gel ${ }^{5}$ and chemical vapor deposition ${ }^{6}$ (CVD) have been employed in the preparation of piezoelectric thin films (PZT, PLZT, ...). R.F. sputtering is a well suited method to grow ferroelectric thin films at very low temperature ${ }^{7}$.

We have performed a series of experimental trials for developing radio-frequency sputtering fabrication and post-annealing treatment technology of PT thin films grown on different substrates.

\section{2- EXPERIMENTAL DETAILS}

A radio-frequency (R.F.) magnetron sputtering system, described previously ${ }^{8}$, was used to prepare PT thin films. The sputtering target was a mixture of $\mathrm{PbO}$ and $\mathrm{TiO}_{2}$ powders (purity 99,9\%) uniaxially cold pressing. Such a target is quick and inexpensive to prepare and usable for many runs. The target diameter and thickness are $25,4 \mathrm{~mm}$ and $2 \mathrm{~mm}$ respectively.

In order to obtain the film stoechiometry, with our sputtering conditions, we have used targets of composition $\mathrm{xPOO}+\mathrm{TiO}_{2}$ with $\mathrm{x}=0,54$. The principal reason is that the sputtering yicld of $\mathrm{Pb}$ is much higher than that of $\mathrm{Ti}^{2}$ in general ${ }^{9}$. The sputtering conditions used in this experiment are summarized in table I. Deposition were performed at room temperature and the process gas is pure argon. The growth rate is in the order of $720 \AA / \mathrm{h}$ on silicon substrate; it is more important on sapphire substrate $(1080 \AA / \mathrm{h})$.

\begin{tabular}{|c|c|}
\hline R.F. Power & $10 \mathrm{~W}$ \\
\hline Intcrelectrode distance & $35 \mathrm{~mm}$ \\
\hline Sputtering gas & $\mathrm{Ar}$ \\
\hline Gas Pressure & $100 \mathrm{mT}$ \\
\hline Substate Temperature & Ambiant \\
\hline
\end{tabular}


The PT films were deposited on different substrates : (0112) and (0001) sapphire, oxidized (100) $-\mathbf{n}$ Silicon (Si) wafers and (100) - n - oxidized Si with thin Ti/Pt alloy layer. The PT film thickness is $3000 \AA$ (measured by profilometry : alpha step 200 TENCOR). The post-annealing treatments were made by conventional furnace annealing (horizontal quartz tube) or rapid thermal annealing (Jipelec Jetstar $4^{10}$ ) in air. The crystal structure and thin films composition were analyzed by X-ray diffractometer and ICP (Inductively Coupled Plasma) respectively. Scanning electron microscopy (SEM) was used for microstructural characterization.

\section{3- RESULTS AND DISCUSSION}

\section{3-1 Conventional annealing}

The films present an excess of $\mathrm{Pb}$ just after the growth; the $(\mathrm{Pb} / \mathrm{Ti})$ ratio of the films was equal to 1,15 . We have voluntary conserved such a $\mathrm{Pb}$ concentration in the film since the growth were made on unheated substrates and so the films were amorphous. A post-deposition annealing was necessary to induce crystallisation in the as grown films and during this treatment $\mathrm{PbO}$ lost from the film.

We have evaluated the lost of $\mathrm{PbO}$ for $\mathrm{PT}$ films grown on $\mathrm{Al}_{2} \mathrm{O}_{3}$ substrates. $\mathrm{PbO}$ loss as a function of annealing temperature is shown in fig. 1. The annealed time was fixed to 2 hours. Since the vapor pressure of $\mathrm{PbO}$

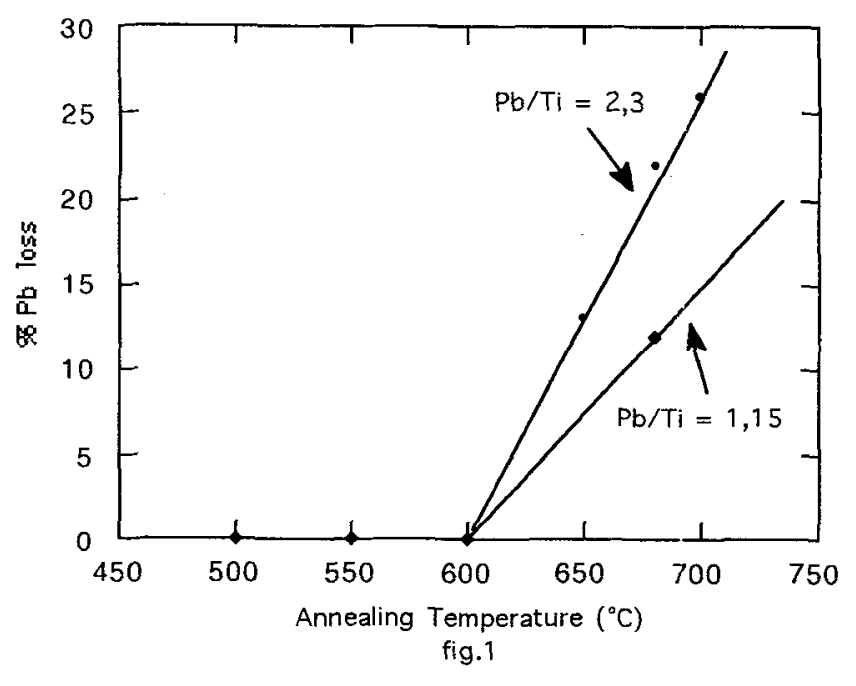
increases with temperature, the loss of $\mathrm{PbO}$ increased with annealing temperature. There is no $\mathrm{PbO}$ evaporation below an annealing temperature of $600^{\circ} \mathrm{C}$. At $680^{\circ} \mathrm{C}$, the loss of $\mathrm{PbO}$ is nearly equal to $14 \%$. The same behaviour is observed for films which contain an important excess of $\mathrm{Pb}(\mathrm{Pb} / \mathrm{Ti}=2,3)$. As we can observed the loss of $\mathrm{PbO}$ due to evaporation increases with increasing $\mathrm{PbO}$ content in the as-deposited films : at $680^{\circ} \mathrm{C}$ the loss of $\mathrm{PbO}$ is $22 \%$. In comparison, it has been reported that $\mathrm{PbO}$ evaporation begins at approximately $600^{\circ} \mathrm{C}$ in bulk $\mathrm{PbTiO}_{3}$ samples ${ }^{11}$. Initial film composition has a little effect on the temperature necessary for $\mathrm{PbO}$ evaporation, but it has a significant influence on the slope of the line relating loss to annealing temperature.

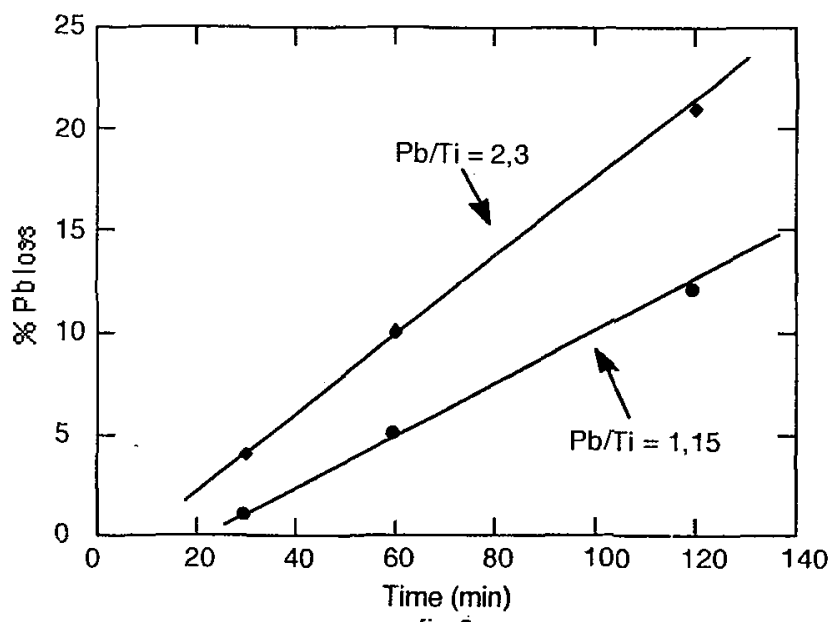

Fig. 2 shows the loss of $\mathrm{PbO}$ as a

function of annealing time ; the annealing temperature is maintained at $680^{\circ} \mathrm{C}$. For $15 \mathrm{~min}$ and $30 \mathrm{~min}$ annealing time there is no $\mathrm{PbO}$ evaporation, it begins at approximately 1 hour $(\sim 4 \%)$. On $\mathrm{Si} / \mathrm{SiO}_{2}$ subsirate, a similar behavior is observed. Films composition with high $\mathrm{PbO}$ excess exhibit $\mathrm{PbO}$ evaporation at $30 \mathrm{~min}$.

So, we can conclude that for films with an as-deposited composition of $\mathrm{Pb} / \mathrm{Ti}=1,15$ a post-deposition annealing at $680^{\circ} \mathrm{C}$ during 2 hours is necessary to have a $\mathrm{Pb} / \mathrm{Ti}$ ratio equal to 1 .

With these annealing parameters, optimized for films composition we must examine the crystallographic structure and the microstructure of PT films. 
As deposited thin films produce $X$ ray diffraction patterns consistent with an amorphous structure. The effect of annealing temperature on crystallization is presented in fig. 3 for films with a starting composition of $(\mathrm{Pb} / \mathrm{Ti})=1,15$ grown on $(0112)$ $\mathrm{Al}_{2} \mathrm{O}_{3}$ substrate, the annealing time is 2 hours. The perovskite structure is initiated at a temperature as low as $450^{\circ} \mathrm{C}$; it is well know that an excess of $\mathrm{PbO}$ favors the perovskite phase formation. The crystallinity of the film increased when the annealing temperature increased, evidenced by higher and sharper XRD peaks. The crystallisation is completed at $680^{\circ} \mathrm{C}$, the tetragonality of the PT film is c/a $=$ 1,057 . For higher temperature $\left(700^{\circ} \mathrm{C}\right)$ the XRD peaks intensity decreased.

It is interesting to note that crystallization and $\mathrm{PbO}$ loss begin at about the same temperature, implying the interdependance of these two diffusion-controlled processes. Fig. 4 shows the evolution of the crystallisation. with the anncaling time; the anncaling temperature is $680^{\circ} \mathrm{C} .15 \mathrm{~min}$. annealing time is sufficient to initiate the perovskite structure ; we can observe an improvement of the crystallinity of the film when the annealing time increased. The PT films have a (101) preferred orientation on (0112) $\mathrm{Al}_{2} \mathrm{O}_{3}$ substrate.

We have made a similar study on (0001) $\mathrm{Al}_{2} \mathrm{O}_{3}$ substrate; the results . are presented fig. 5

The (101) preferred orientation is also observed.

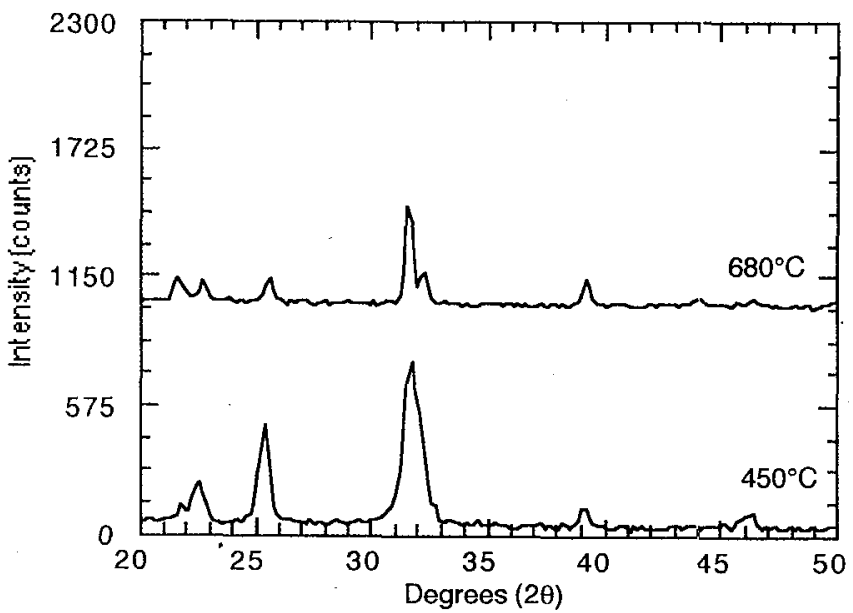

fig. 3
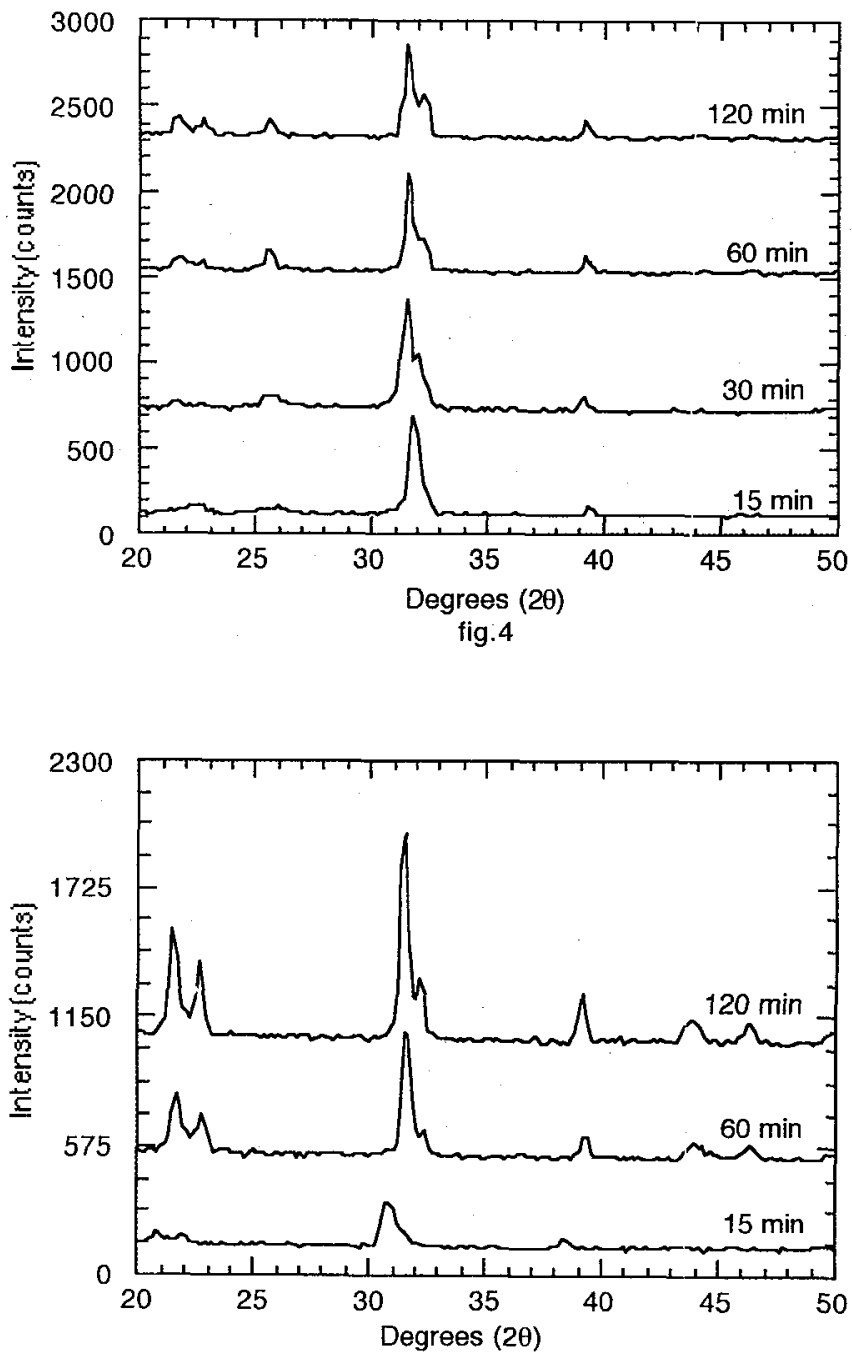

fig. 5 
The annealing parameters : $680^{\circ} \mathrm{C}$ during 2 hours are also perfectly well adapted to $\mathrm{Si} / \mathrm{SiO}_{2}$ and $\mathrm{Si} / \mathrm{SiO} / \mathrm{Ti} / \mathrm{Pt}$ substrates as we can observed fig. 6 .

The surface morphology of PT films was observed with a scanning electron microscope (SEM).

Fig. 7 shows the SEM picture for the PT film on $\mathrm{Al}_{2} \mathrm{O}_{3}$ substrate after it was subjected to furnacc annealing to $680^{\circ} \mathrm{C}$ for 2 hours. The film have a dense morphology without porosity. Fig. 8 shows the SEM observation of the edge of a $\mathrm{Si} / \mathrm{SiO}_{2} / \mathrm{PT}$ sample, obtained by simple cleaving, before and after annealing at $680^{\circ} \mathrm{C}$ during 2 hours (fig. $8 \mathrm{a}$ and $8 \mathrm{~b}$ respectively). After annealing, the columnar structure disappear and the film is well densified.
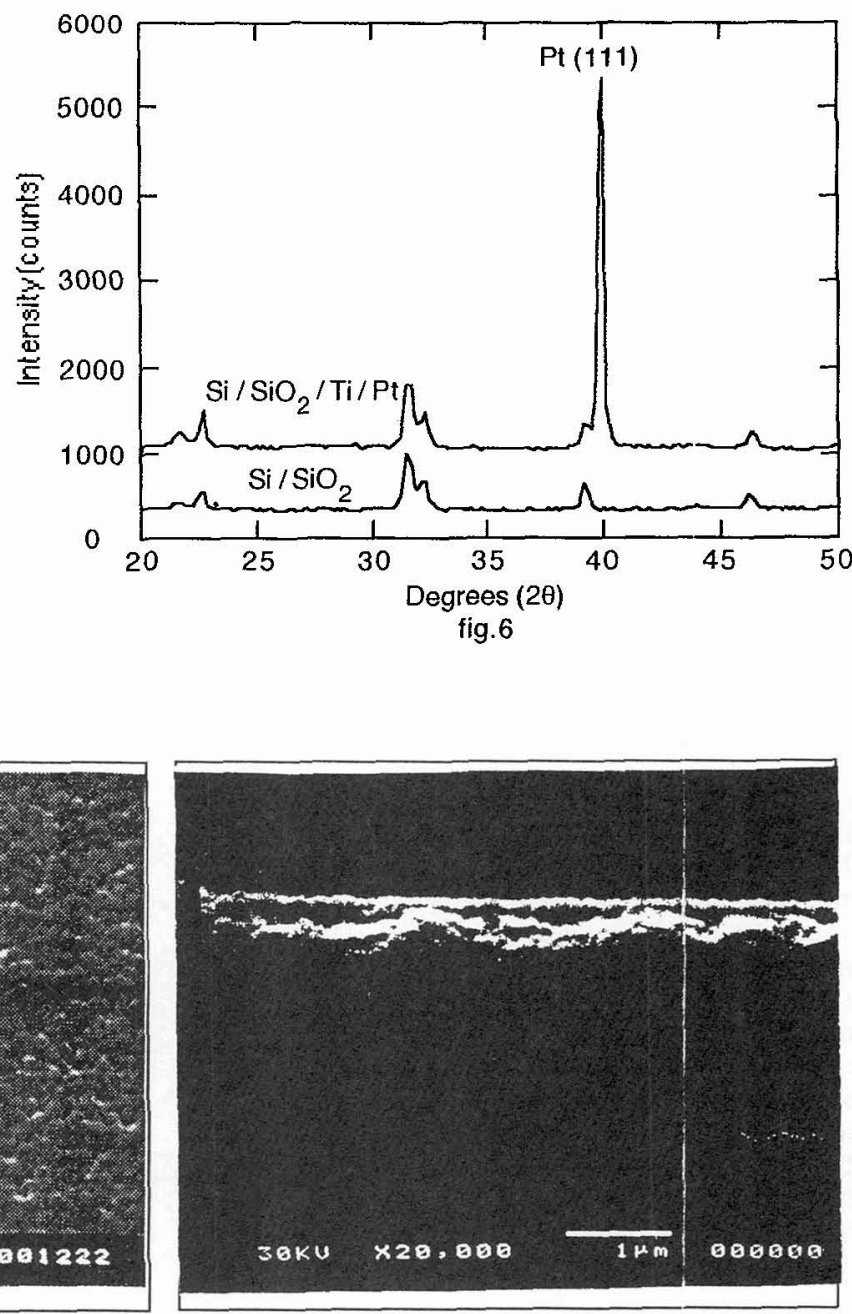

fig.8-a

fig. 7

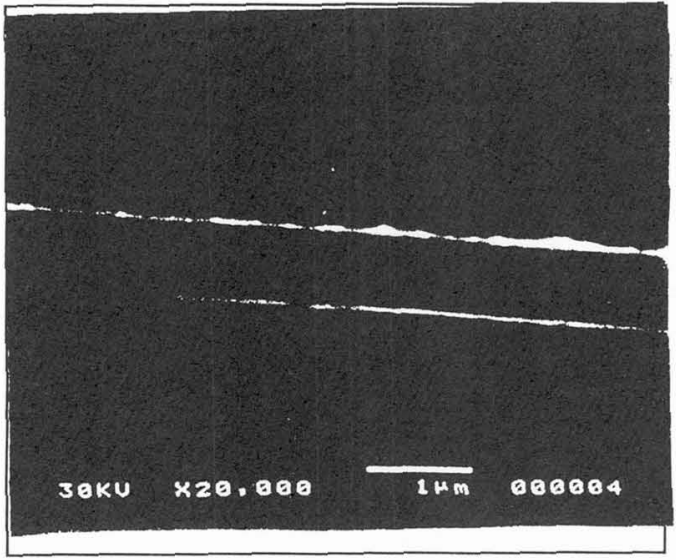

fig.8-b 
The inconvenient of such annealing treatment is the high annealing temperature which is not always compatible with semiconductor processing. Therefore, efforts have been made to reduce the processing temperature or the annealing time.

In this practice, rapid thermal annealing (RTA), initially used in semiconductor technology has been shown to be a suitable technique to crystallize ferroelectric thin film ${ }^{12,13}$.

RTA, with radiations from halogen lamps, has advantage over conventional furnace annealing to much shorter annealing times necessary to crystallize and so to minimized film-substrate interface reactions.

\section{3-2 Rapid thermal annealing}

We have studied the influence of the annealing parameters on PT films crystallization. The RTA system used in this work was a commercial JETSTAR 4 manufactured by JIPELEC. The initial composition of films is given by $\mathrm{Pb} / \mathrm{Ti}=1,15$; the film are grown on $\mathrm{Al}_{2} \mathrm{O}_{3}$ substrates. An important property of the RTA, by comparison with conventional annealing, is to lower the crystallisation temperature. Firstly, we have determined the annealing temperature necessary to crystallize the film when the annealing time is fixed to $30 \mathrm{~s}$. Fig. 9 shows that at $500^{\circ} \mathrm{C}$ the perovskite structure is present without any second phase (in particular pyrochlore phase).

At $600^{\circ} \mathrm{C}$ (fig. 10) the crystallinity of the film is improved (higher XRD peaks). At higher temperature any improvement was observed. The degree of crystallinity (peaks intensity) is the same to that obtained during $30 \mathrm{~min}$. at $680^{\circ} \mathrm{C}$ by conventional treatment.

When the annealing time is reduced, the annealing temperature must be increased. For exemple for an annealing time of $5 \mathrm{~s}$, the annealing temperature at which the perovskite structure is well defined was $680^{\circ} \mathrm{C}$ (fig. 11). The tetragonality of the PT film is $\mathrm{c} / \mathrm{a}=1,062$ (the theoritical value is 1,063 ).
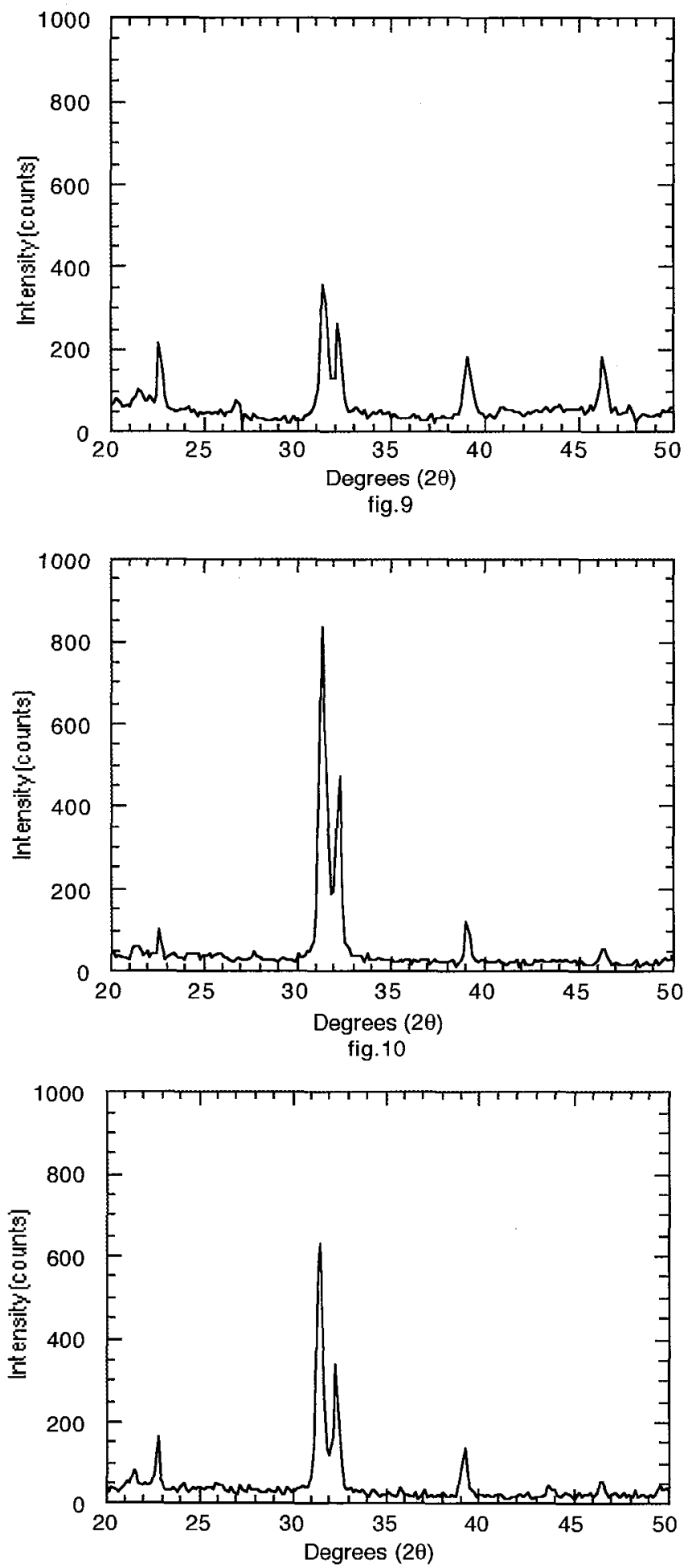

fig. 11 
Fig. 12 shows the microstructure of a PT film annealing by RTA $\left(680^{\circ} \mathrm{C}-30 \mathrm{~s}\right)$; the annealed film attained a dense morphology without porosity and a very fine grain size. It is directly related to the fast firing; this treatment improved the densification and limited the grain growth.

Further studies were investigated to optimize the process.

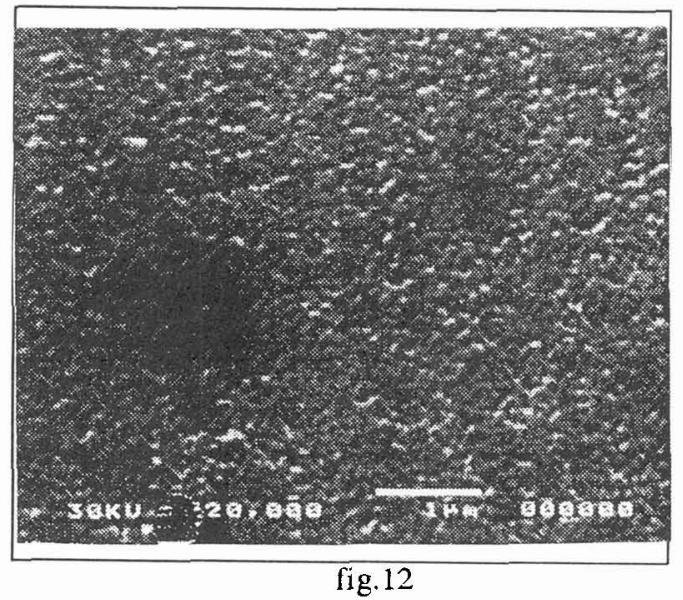

\section{4- CONCLUSION}

PT films have been obtained by a sputtering technique with a post-deposition conventional or rapid thermal annealing treatment.

The conventional thermal process has been optimized in terms of composition, structure and microstructure on different substrates.

By rapid thermal annealing, the structure is completed at $600^{\circ} \mathrm{C}$ for $30 \mathrm{~s}$ without pyrochlore phase. In conventional annealing, the temperature to obtain the perovskite phase is about $680^{\circ} \mathrm{C}$ and an annealing time of about $2 \mathrm{~h}$ is necessary to complete the crystallisation. These results confirm that rapid thermal processing is a very promising technique for fabrication of PT films (or other piezoelectric thin films).

\section{REFERENCES}

[1] Y. IIJIMA, Jpn. Journ. Appl. Phys., 24 (3), p 17 (1985).

[2] D.W. BONDURANT, Proc. Colorado Microelectronics Conf., Univerśity of Colorado - Colorado Springs (1989).

[3] H. HU, S.B. KRUPANIDHI, Journ. Appl. Phys., 74 (5), p 3373 (1993).

[4] O. AUCIELLO et al, Journ. Appl. Phys., 73 (10), p 5197 (1993).

[5] MARK D. CARPER, P.P. PHULE, Journ. Appl. Lett., 63 (2), p 153 (1993).

[6] Z. QIAN et al, Journ. Appl. Phys., 74 (11), p 7857 (1993).

[7] XINGJIRO et al, Appl. Phys. Lett., 63 (17), p 2345 (1993).

[8] D. REMIENS et al, Journ. Europ. Ceram. Soc. (à paraître).

[9] D. REMIENS et al, Third ECRS, Madrid (Spain) (1993).

[10] D.A. NORTHROP, J. Am. Ceram. Soc., 50 (9), p 441 (1967).

[11] C.V.R. VASANT KUMAR et al, Appl. Phys. Lett., 58 (11), p 1161 (1991).

[12] L. SHI et al, Integrated Ferroelectrics, 1, p 111 (1992). 